\title{
Factores que determinan la viabilidad de los emprendimientos.
}

\section{Factors that determine the viability of the ventures}

\author{
José Gabriel Pilaguano Mendoza. ${ }^{1}$, Homero Eudoro Suárez Navarrete. ${ }^{2}$, Marcelo Eduardo \\ Sánchez Salazar. ${ }^{3} \&$ William Patricio Cevallos Silva. ${ }^{4}$
}

\section{DOI: https://doi.org/10.33262/visionariodigital.v3i2.393}

\section{Resumen.}

La propuesta permite determinar que los emprendimientos aportan al desarrollo económico, el presente estudio permitirá construir un proceso concertado con el aporte de las capacidades y derechos ciudadanos en ámbitos territoriales y político-administrativos, abarcará la construcción de unidades de planificación, de diseño de estrategias y proyectos de desarrollo con base en los recursos, necesidades e iniciativas locales. Este proceso incorpora las dinámicas del desarrollo sectorial, funcional y territorial, que se emprenden desde el Estado, las organizaciones sociales y la empresa privada en el territorio. Los emprendimientos son de forma integral; es decir, incorpora en el diseño de sus planes al conjunto de dimensiones presentes en el territorio: social, económico, ambiental. Por ello, iniciar emprendimientos de desarrollo local debe permitir favorecer el crecimiento económico, la democracia política y el progreso social, de modo que se vaya alcanzando un desarrollo humano sostenible. Es un proceso que promoverá el gobierno local en alianza con otros agentes, con el propósito de ampliar la base económica local, acumulando y capitalizando sus excedentes, fortaleciendo el tejido económico y generando el desarrollo

\footnotetext{
${ }^{1}$ Escuela Superior Politécnica de Chimborazo, Facultad de Administración de Empresas, Riobamba, Ecuador, gpilaguano@espoch.edu.ec

2 Escuela Superior Politécnica de Chimborazo, Facultad de Administración de Empresas, Riobamba, Ecuador, h_suarez@espoch.edu.ec

${ }^{3}$ Escuela Superior Politécnica de Chimborazo, Facultad de Administración de Empresas, Riobamba, Ecuador, marcelo.sanchez@espoch.edu.ec

${ }^{4}$ Escuela Superior Politécnica de Chimborazo, Facultad de Administración de Empresas, Riobamba, Ecuador, patricio.cevallos@espoch.edu.ec
} 
de un entorno competitivo, que posibilite el desarrollo de las empresas, la generación de empleo local y luchar de manera efectiva contra la pobreza.

Palabras claves: ciencias económicas y administrativas, proyecto de factibilidad, desarrollo económico, emprendimientos.

\begin{abstract}
.
The proposal allows to determine that the enterprises contribute to economic development, the present study will allow building a concerted process with the contribution of the capacities and citizen rights in territorial and political-administrative spheres, it will cover the construction of planning units, strategy design and development projects based on local resources, needs and initiatives. This process incorporates the dynamics of sectoral, functional and territorial development, which are undertaken by the State, social organizations and private companies in the territory. The ventures are of integral form; that is, it incorporates in the design of its plans the set of dimensions present in the territory: social, economic, environmental. For this reason, initiating local development projects must allow economic growth, political democracy and social progress to be fostered, so that sustainable human development can be achieved. It is a process that will promote the local government in alliance with other agents, with the purpose of expanding the local economic base, accumulating and capitalizing its surpluses, strengthening the economic fabric and generating the development of a competitive environment, which enables the development of companies, the generation of local employment and fight effectively against poverty.
\end{abstract}

Keywords: Economic and administrative sciences, project of feasibility, economic development, entrepreneurships.

\title{
Introducción.
}

Para conocer sobre posibles propuestas de emprendimientos es indispensable conocer el concepto sobre DESARROLLO ECONÓMICO LOCAL según Francisco Alburquerque quien manifiesta "Es un proceso reactivador de la economía y dinamizador de la sociedad local, que mediante el aprovechamiento eficiente de los recursos endógenos (internos) existentes en una determinada zona, es capaz de estimular su crecimiento económico, crear empleo y mejorar la calidad de vida de la comunidad local".

Con la ejecución de la propuesta se pretende mejorar la calidad de vida de la población del territorio a través de la implementación de acciones conjuntas que ayuden a la generación del empleo, al fortalecimiento de micro y pequeñas unidades productivas, asociaciones, innovación tecnológica, redes de cooperación, redes de comercialización, formación del recurso humano y que conlleve al crecimiento económico de la población. 
El enfoque de Desarrollo Económico Local, promueve una gestión en la que los emprendimientos deben desarrollar alternativas económicas que permitan trascender de las tradicionales competencias que las asocian a entidades meramente prestadoras de servicios (limpieza, mataderos, administración de mercados, construcción de infraestructura o equipamiento vial y social) para asumir un rol de promotores del desarrollo integral y la dinamización de sus economías.

\section{Desarrollo.}

\section{Concepto de proyecto}

Un proyecto es la búsqueda de una solución inteligente al planteamiento de un problema, la cual tiende a resolver una necesidad humana. En este sentido puede haber diferentes ideas, inversiones de monto distinto, tecnología y metodologías con diverso enfoque, pero todas ellas destinadas a satisfacer las necesidades del ser humano en todas sus facetas, como pueden ser: educación, alimentación, salud, ambiente, cultura, etcétera. (Baca U, 2010, pág. 2)

\section{Importancia de la elaboración de proyectos}

La ejecución de proyectos productivos constituye el motor del desarrollo de una región o país, razón por la cual las instituciones financieras del orden regional, nacional e internacional tienen como objetivos la destinación de recursos para la financiación de inversiones que contribuyen a su crecimiento económico y beneficios sociales. (Padilla, 2011, pág. 5)

\section{Tipos de proyectos}

Existen diferentes tipos de proyectos, cada uno se dirige a solucionar determinadas barreras al desarrollo, y tiene costos y beneficios específicos asociados, así:

- Dependientes

- Independientes

- Mutuamente excluyentes

- Productivos

- De infraestructura económica

- De infraestructura social

- Proyectos de inversión privada

- Proyectos de inversión pública.

- Proyectos de inversión social 
- Creación de nuevas unidades de negocios o empresas

- Cambios en las unidades de negocios existentes

- Proyectos de infraestructura

- Proyectos de fortalecimiento de capacidades sociales o gubernamentales (Padilla C, 2011, págs. 5-15)

\section{Proyecto de inversión}

Un proyecto de inversión es una propuesta técnica y económica para resolver un problema de la sociedad utilizando los recursos humanos, materiales y tecnológicos disponibles, mediante un documento escrito que comprende una serie de estudios que permiten al inversionista saber si es viable su realización (Padilla C, 2011, pág. 2)

\section{Estudio de factibilidad}

Según Sapag (2011) manifiesta que "El estudio de factibilidad es un instrumento que sirve para orientar la toma de decisiones en la evaluación de un proyecto”. (pág. 20)

\section{Ciclo de vida de los proyectos}

El ciclo de vida de un proyecto de inversión se inicia con un problema originado en una necesidad, a la cual debe buscársele solución coherente, generalmente, los proyectos de inversión atraviesan por cuatro grandes fases: pre inversión, inversión operación, y evaluación de resultados. (Padilla C, 2011, pág. 2)

Estudios que integran un proyecto de inversión

- Estudio de mercado

- Estudio de técnico

- Estudio administrativo - legal

- Estudio financiero

- Evaluación económica.

- Evaluación ambiental (Lara, 2011, págs. 19-20)

\section{Estudio de mercado}

Con el nombre de estudio de mercado se denomina a la primera parte de la investigación formal del estudio. Consta de la determinación y cuantificación de la demanda y la oferta, el análisis de los precios y el estudio de la comercialización. (Baca U, 2010, pág. 7) 


\section{Definición de mercado}

Según Lara (2011) manifiesta que “ el mercado es el lugar físico o virtual donde se reúnen compradores llamados demandantes y vendedores denominados ofertantes, para realizar transacciones de compra y venta de bienes y servicios que satisfagan necesidades" (p.29).

\section{Demanda}

Según Lara (2011) "es la suma de las adquisiciones de un bien o servicio por parte de las personas físicas y/o jurídicas, para satisfacer sus necesidades” (pag.31)

\section{Segmentación del mercado}

Es determinar las características (edad. sexo, raza, ubicación, ingresos) de los mercados y dividirlos en varias variables. Es una de las herramientas de mercadotecnia que nos permite realizar un análisis del mercado, en donde, un universo heterogéneo, es dividido en grupos con al menos una característica homogénea. Ejemplo: mujeres, ecuatorianas, que vivan en ciudades de más de 1 millón de personas, que tengan entre los 15 a 49 años. (Lara, 2011, pág.48)

\section{Oferta}

Según Baca (2010) "La oferta es la cantidad de bienes o servicios que un cierto número de oferentes (productores) está dispuesto a poner a disposición del mercado a un precio determinado" (p.41).

\section{Determinación de la demanda potencial insatisfecha}

Es la cantidad de bienes o servicios que es probable que el mercado consuma en los años futuros, sobre la cual se ha determinado que ningún productor actual podrá satisfacer si prevalecen las condiciones en las cuales se hizo el cálculo. (Baca U, 2010, pág. 43)

\section{Estudio financiero}

En el estudio económico financiero se especifican las necesidades de recursos a invertir, con detalles de las cantidades y fechas para los diversos ítems señalados, su forma de financiación (aporte propio y créditos) y las estimaciones de ingresos y egresos para el período de vida útil del proyecto. El estudio económico financiero permite establecer los recursos que demanda el proyecto, los ingresos y egresos que generará y la manera como se financiará. (Padilla C, 2011, pág. 186) 
Inversiones de un proyecto

Se denomina inversiones a todos los gastos que se efectúan por unidad de tiempo para poder adquirir los factores productivos (mano de obra, materias primas y capital productivo y otros), necesarios para poder implementar el proceso productivo del bien o servicio, el mismo que generara beneficios, en el periodo establecido como vida útil del proyecto. (Lara, 2011, pág. 163)

\section{Inversión fija o tangible}

según Lara (2011) manifiesta que "son todo tipo de inversiones realizadas en bienes tangibles y duraderos para la operación y durante la vida útil del proyecto" (pag.164)., así tenemos compra de terrenos, construcción de obras físicas, compra de maquinaria, equipos, aparatos, instrumentos, herramientas, muebles, enseres y vehículos.

\section{Inversiones diferidas o intangibles}

Según Padilla (2011) manifiesta que "Los activos intangibles están referidos al conjunto de bienes propiedad de la empresa, necesarios para su funcionamiento, e incluyen investigaciones preliminares, gastos de estudio, adquisición de derechos, patentes de invención, etc." (pág. 192).

\section{Capital de trabajo inicial}

Contablemente se define como la diferencia entre el activo circulante y pasivo circulante, está representado por el capital adicional necesario para que funcione una empresa, es decir, los medios financieros necesarios para la primera producción mientras se perciben ingresos: materias primas, sueldos y salarios, cuentas por cobrar, almacén de productos terminados y un efectivo mínimo necesario para sufragar los gastos diarios de la empresa. (Padilla C, 2011, pág. 192)

\section{Inversión total}

Aquí se debe hacer una adecuada presentación de la información financiera teniendo en cuenta la realización de un cómputo de los costos correspondientes a la inversión fija, la inversión diferida y al capital de trabajo necesario para la instalación y operación del proyecto. (Padilla C, 2011, pág. 192)

\section{Costos del proyecto}


Según Lara (2011) manifiesta que "los costos son todos aquellos egresos de dinero que se deben realizar en un proyecto en el proceso de producción de un bien o servicio" (pag.177).

\section{Gastos del proyecto}

Según Lara (2011) manifiesta que "Son todos los egresos que se realizan en un proyecto y que no pertenecen a los procesos de producción, si no como elemento de apoyo a mismo, y también para la distribución y comercialización del mismo" (pag.183).

\section{Gastos administrativos}

Son todos los egresos que se realizan en la normal operación del proyecto y se refieren a todos los que se identifique con los procesos de administración del proyecto. Esto significa tomar en cuenta los gastos de planificación, control, evaluación, otro. Entre estos tipos de gastos tenemos: personal servicios contratados, impuestos fiscales y municipales, multas e interese, mantenimiento y reparaciones, seguros, amortizaciones, alquiler, gastos generales, comisiones, honorarios, otros. (Lara, 2011, pág. 184)

\section{Gastos de ventas}

Son todos los egresos que se destinan al proceso de vender los bienes y servicios producidos por las actividades propias del proyecto que se realiza en la normal operación dl mismo. Comprende las siguientes subcuentas: los costos de planificación y programación de ventas, promoción administración de ventas, publicidad, propaganda, marketing, expedición y envío, reclamos, atención al cliente, comisiones a vendedores. (Lara, 2011, pág. 188)

\section{Gastos financieros}

Según Córdova (2011) manifiesta que "contempla aquellos intereses que se originan en la financiación de las inversiones de la empresa y los resultados deficitarios durante la vida útil del proyecto" (pag.203).

\section{Depreciación}

Según Lara (2011) manifiesta que "es la pérdida del valor agregado de los activos fijos que sufren de su vida útil, por su desgaste normal, debido al uso de los mismos en el proceso de producción de un proyecto" (pag.193).

Ingresos 
Según Lara (2011) manifiesta que "Son las entradas de dinero que el proyecto tiene, principalmente por las actividades normales de sus operaciones y a veces por otras actividades" (pag197).

Ingresos operacionales: son los ingresos que se producen por las actividades normales del proyecto.

Ingresos no operacionales: son aquellos producidos por actividades no operacionales del proyecto y generalmente son; intereses ganados por inversiones de tipo financiera, ventas de activos fijos a través del valor del salvamento. (Lara, 2011, pág. 198)

\section{Punto de equilibrio}

Según Baca (2010) manifiesta que "El punto de equilibrio es el nivel de producción en el que los ingresos por ventas son exactamente iguales a la suma de los costos fijos y los variables" (pág. 148).

\section{Flujo de caja proyectado}

Según Padilla (2011) manifiesta que "Es un estado financiero que mide los movimientos de efectivo, excluyendo aquellas operaciones que, como la depreciación y amortización, constituyen una salida de dinero". (pág. 210)

\section{Balance de situación inicial}

Según Lara (2011) manifiesta que "Es importante establecer un balance de situación inicial proyectado al primer año de vida del proyecto, así como el estado de resultados, aunque no indispensable" (pag.213).

\section{Estado de resultados}

La finalidad del análisis del estado de resultados o de pérdidas y ganancias es calcular la utilidad neta y los flujos netos de efectivo del proyecto, que son, en forma general, el beneficio real de la operación de la planta, y que se obtienen restando a los ingresos todos los costos en que incurra la planta y los impuestos que deba pagar. Esta definición no es muy completa, pues habrá que aclarar que los ingresos pueden prevenir de fuentes externas e internas y no sólo de la venta de los productos. (Baca U, 2010, pág. 150)

\section{Evaluación financiera}


Este tipo de evaluación mide el grado de rendimiento de la inversión a precios de mercados. Es la más común en todos los proyectos y muchas veces se confunde con la evaluación económica. La evaluación financiera se realiza específicamente en proyectos de inversión privada. (Lara, 2011, pág. 240)

\section{Costo de oportunidad}

El coste de oportunidad es el coste de la alternativa a la que renunciamos cuando tomamos una determinada decisión, incluyendo los beneficios que podríamos haber obtenido de haber escogido la opción alternativa. Por lo tanto, el coste de oportunidad son aquellos recursos que dejamos de percibir o que representan un coste por el hecho de no haber elegido la mejor alternativa posible, cuando se tienen unos recursos limitados (generalmente dinero y tiempo). El término coste de oportunidad también es denominado como "el valor de la mejor opción no seleccionada. (Pedrosa, 2017)

\section{Valor actual neto (VAN)}

Según Lara (2011) manifiesta que "Es la suma algebraica de la inversión total con signo negativo, más los flujos de cada año, pero actualizados a una tasa referencial” (pag.143)

Según Lara (2011) en otra definición dice que "el VAN es el valor monetario que resulta de restar la suma de los flujos descontados a la inversión inicial”. (pag.143)

\section{Tasa interna de retorno}

Es la tasa que convierte al VAN en cero, esto significa que la totalidad de los flujos positivos actualizados son exactamente igual a la totalidad de los flujos negativos actualizados, lo que significa que es la tasa más alta que los inversionistas pueden pagar sin perder su dinero. (Lara, 2011, pág. 252)

\section{Relación beneficio costo}

Según Lara (2011) manifiesta que "Es la relación entre todos los ingresos en efectivo actualizado del proyecto dividido para los egresos de efectivo actualizados incluyendo la inversión. Este indicador se utiliza para medir el éxito del proyecto” (pág. 255).

Según Lara (2011) en otra conceptualización manifiesta que "La relación beneficio costo es el cociente entre los flujos descontados y la inversión inicial, a diferencia del VAN en lugar de restar o sumar los flujos de inversión realiza un cociente, por lo tanto, este indicador es un número" (pág. 255). 
Periodo de recuperación de la inversión

Según Padilla (2011) manifiesta que "el PRI Es un instrumento que permite medir el plazo de tiempo que se requiere para que los flujos netos de efectivo de una inversión recuperen su costo o inversión inicial”. (Padilla C, 2011, pág. 234)

\section{Resultados.}

Luego del análisis de los resultados obtenidos y aplicando la metodología y el marco teórico descrito en la investigación, se permite realizar la determinación de variables, potencialidades y ejes que permitan emprendimientos de éxito y de desarrollo económico.

\section{Matriz de potencialidades.}

La técnica de investigación aplicada permitió determinar varios problemas y potencialidades que los actores locales, representantes de instituciones públicas y privadas tienen para el componente económico.

Tabla 1: Matriz de potencialidades Eje Económico

\begin{tabular}{|c|c|c|}
\hline \multicolumn{3}{|c|}{ Económico } \\
\hline Variables & Potencialidades & Problemas \\
\hline \multirow{4}{*}{ Trabajo y Empleo } & \multirow{4}{*}{$\begin{array}{l}\text { Disponibilidad de mano de } \\
\text { obra calificada }\end{array}$} & Poco desarrollo industrial. \\
\hline & & $\begin{array}{l}\text { Proveedores de servicios y de materias primas, } \\
\text { sin valor agregado. }\end{array}$ \\
\hline & & $\begin{array}{l}\text { Los profesionales formados en la ciudad migran } \\
\text { para encontrar mejores oportunidades laborales. }\end{array}$ \\
\hline & & $\begin{array}{l}\text { Incumplimiento de las empresas para la } \\
\text { aplicación de la ley sobre inclusión laboral }\end{array}$ \\
\hline Estructura productiva & $\begin{array}{l}\text { Diagnóstico de necesidades } \\
\text { primordiales en todo el país. }\end{array}$ & $\begin{array}{l}\text { Ausencia de una política pública y resoluciones } \\
\text { de desarrollo económico }\end{array}$ \\
\hline $\begin{array}{l}\text { Relación entre sectores } \\
\text { económicos }\end{array}$ & \begin{tabular}{|lrr} 
Posibilidades & de \\
apalancamiento para & los \\
sectores primario & $\mathrm{y}$ \\
secundario. & \\
\end{tabular} & $\begin{array}{l}\text { Débil encadenamiento productivo entre los } \\
\text { sectores con excesiva concentración de ingresos } \\
\text { en un sólo sector. }\end{array}$ \\
\hline $\begin{array}{l}\text { Principales actividades } \\
\text { económicas }\end{array}$ & $\begin{array}{l}\text { Incorporación de valor } \\
\text { agregado al sector primario, } \\
\text { mediante la agroindustria, el } \\
\text { desarrollo de tecnología. }\end{array}$ & Estrechos márgenes de ganancia. \\
\hline $\begin{array}{l}\text { Establecimientos } \\
\text { económico-productivos }\end{array}$ & $\begin{array}{l}\text { Existe una base considerable } \\
\text { de establecimientos } \\
\text { comerciales, los cuales } \\
\text { deberían incorporar a su } \\
\text { oferta productos locales. } \\
\end{array}$ & Poco desarrollo industrial \\
\hline Factores productivos & $\begin{array}{l}\text { La mayoría de las unidades } \\
\text { productivas } \quad \text { agropecuarias }\end{array}$ & Elevar la productividad. \\
\hline
\end{tabular}




\begin{tabular}{|c|c|c|}
\hline & facilita el desarrollo & \\
\hline $\begin{array}{l}\text { Seguridad y soberanía } \\
\text { alimentaria }\end{array}$ & $\begin{array}{l}\text { La población aún se alimenta } \\
\text { con productos propios de la } \\
\text { zona como productos } \\
\text { orgánicos. }\end{array}$ & $\begin{array}{l}\text { La producción orgánica y agroecológica para } \\
\text { certificación. }\end{array}$ \\
\hline $\begin{array}{l}\text { Proyectos Estratégicos } \\
\text { Nacionales }\end{array}$ & Centro de negocios & Proyectos estratégicos nacionales. \\
\hline $\begin{array}{l}\text { Infraestructura de } \\
\text { apoyo a la producción }\end{array}$ & $\begin{array}{l}\text { Al ser la capital de la } \\
\text { provincia, Riobamba se } \\
\text { convierte en el centro de } \\
\text { acopio y comercialización de } \\
\text { toda clase de productos. }\end{array}$ & $\begin{array}{l}\text { Existe infraestructura para la comercialización } \\
\text { (Mercado mayorista, mercados de la ciudad, } \\
\text { plazas) sin embargo existe carencia de } \\
\text { infraestructura. }\end{array}$ \\
\hline $\begin{array}{l}\text { Mercado de capitales y } \\
\text { finanzas }\end{array}$ & $\begin{array}{l}\text { Existe gran variedad de } \\
\text { opciones de financiamiento } \\
\text { para diversos estratos y } \\
\text { segmentos de mercado, como } \\
\text { cooperativas, banca pública y } \\
\text { banca privada. }\end{array}$ & $\begin{array}{l}\text { Existe una alta concentración de créditos en el } \\
\text { sector comercial y muy pocas opciones para los } \\
\text { emprendedores y empresarios. }\end{array}$ \\
\hline
\end{tabular}

Fuente: Investigación de campo

Elaborado por: Los Autores

\section{FODA PARA EL DESARROLLO DE EMPREDIMIENTOS}

Para conocer las fortalezas, debilidades, amenazas y oportunidades es necesario conocer los aspectos relevantes en el desarrollo económico.

Tabla 2: Matriz FODA

\begin{tabular}{|c|c|}
\hline FORTALEZAS & DEBILIDADES \\
\hline $\begin{array}{l}\text { Alianzas estratégicas con el sector público y } \\
\text { privado }\end{array}$ & 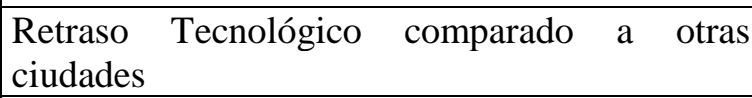 \\
\hline $\begin{array}{l}\text { Puesta en marcha de iniciativas locales a través } \\
\text { de los GAD's. }\end{array}$ & Inexistencia de fuentes de empleo \\
\hline Oferta abundante de capital humano & $\begin{array}{l}\text { Concientización ecológica y cultural en la } \\
\text { ciudadanía. }\end{array}$ \\
\hline $\begin{array}{l}\text { Tener las vocaciones económicas tales como: } \\
\text { agricultura, ganadería, turismo, construcción, } \\
\text { logística y transporte, manufactura }\end{array}$ & $\begin{array}{l}\text { Falta de políticas públicas en beneficio de la } \\
\text { colectividad }\end{array}$ \\
\hline OPORTUNIDADES & $\mathbf{A S}$ \\
\hline $\begin{array}{l}\text { Voluntad política para generar y poner en } \\
\text { marcha nuevos proyectos }\end{array}$ & decisiones \\
\hline Avances tecnológicos a través de la academia & $\begin{array}{l}\text { ección de recursos por parte del } \\
\text { al }\end{array}$ \\
\hline $\begin{array}{|lcr|}\begin{array}{l}\text { Convenios internacionales } \\
\text { pasantías y capacitaciones }\end{array} & \text { realizar } \\
\end{array}$ & Abandono de la Identidad cultural \\
\hline $\begin{array}{l}\begin{array}{l}\text { Presencia de varias industrias locales } \\
\text { nacionales }\end{array} \\
\text { nacion }\end{array}$ & 1 \\
\hline
\end{tabular}


Fuente: Investigación de campo.

Elaborado por: Los Autores.

Las estrategias se articularán como eje principal en el Desarrollo Económico se constituye en la principal herramienta y guía para el sector Público, Privado, Financiero y Academia, es necesario realizar la articulación con las actores de cambio que son los encargados de impulsar este proceso y estos son tanto públicos como privados, y se resumen básicamente en las autoridades locales, universidades, cámaras empresarias, centros de formación, agencias de desarrollo local, bancos, cooperativas y otras.

Estos actores de cambio son importante y que transiten por estos procesos de generación de confianza que potenciarían su accionar., entre los actores de cambio del sector Público, Privado, Academia, Ongs, Instituciones Financieras, Institutos tenemos: Gobierno Autónomo Descentralizado, Ministerio de Industrias y Productividad, Ministerio de Agricultura, Ganadería, Acuacultura y Pesca, Instituto Nacional de Economía Popular y Solidaria; Agencia Reguladora de Control Sanitario, Agrocalidad, actores privados: las Cámaras de la Pequeña Industria, Comercio, Academia: Instituciones de Educación Superior, las ONGs, Instituciones Financieras.

A continuación, se detalla los ejes estratégicos para el desarrollo de emprendimientos que coadyuven al desarrollo económico.

Tabla 3: Ejes estratégicos para el desarrollo de emprendimientos

\begin{tabular}{|c|c|c|}
\hline $\begin{array}{c}\text { EJES } \\
\text { ESTRATÉGICOS } \\
\end{array}$ & $\begin{array}{c}\text { PLANES, PROGRAMAS Y } \\
\text { PROYECTOS IMPULSORES }\end{array}$ & OBJETIVO \\
\hline \multirow{3}{*}{$\begin{array}{l}\text { 1.- Programa de } \\
\text { industria e Innovación }\end{array}$} & $\begin{array}{l}\text { 1.- Centros de almacenamiento, y } \\
\text { agregador de valor } \\
\text { agroalimenticios, y derivados de } \\
\text { lácteos. }\end{array}$ & $\begin{array}{l}\text { Apalancar los sectores productivos } \\
\text { agroalimenticios y derivados tratando } \\
\text { de evitar la caída de precios y de } \\
\text { competitividad de la zona. }\end{array}$ \\
\hline & 2.- Plan de Industrialización & $\begin{array}{l}\text { Repotenicalizar la industria } \\
\text { incentivando el desarrollo y } \\
\text { procesamiento de nuevos productos. }\end{array}$ \\
\hline & 3.- Fomento a la manufactura & $\begin{array}{l}\text { Desarrollar y empoderar los sectores } \\
\text { primarios y secundarios para generar } \\
\text { una fuente de productos de } \\
\text { exportación y consumo interno con } \\
\text { alto valor agregado. }\end{array}$ \\
\hline $\begin{array}{l}\text { 2.- Programa de } \\
\text { producción local y } \\
\text { consumo responsable }\end{array}$ & $\begin{array}{l}\text { 4.- Estudio de las principales } \\
\text { cadenas productivas }\end{array}$ & $\begin{array}{l}\text { Determinar las cadenas productivas } \\
\text { como base para el desarrollo de } \\
\text { nuevos emprendimientos }\end{array}$ \\
\hline
\end{tabular}




\begin{tabular}{|c|c|c|}
\hline & $\begin{array}{l}\text { 5.- Encadenamiento de productos } \\
\text { turísticos urbano- rural. }\end{array}$ & $\begin{array}{l}\text { Impulsar los proyectos de turismo del } \\
\text { cantón promocionando el tránsito } \\
\text { turístico urbano-rural. }\end{array}$ \\
\hline & $\begin{array}{l}\text { 6.- Campaña del consumo } \\
\text { responsable de los productos }\end{array}$ & $\begin{array}{l}\text { Propender el consumo de productos } \\
\text { de la zona a través de una campaña de } \\
\text { promoción dirigida al conocimiento } \\
\text { de sus beneficios. }\end{array}$ \\
\hline \multirow{6}{*}{$\begin{array}{l}\text { 3.- Programa de } \\
\text { fomento al capital } \\
\text { humano }\end{array}$} & $\begin{array}{l}\text { 7.- Programa de capacitación para } \\
\text { los diferentes actores de la } \\
\text { economía }\end{array}$ & $\begin{array}{l}\text { Implementar técnicas de aprendizaje y } \\
\text { aplicación de desarrollo social y } \\
\text { solidario en los actores de la } \\
\text { economía }\end{array}$ \\
\hline & $\begin{array}{l}\text { 8.- Programa de innovación } \\
\text { productiva para el fortalecimiento } \\
\text { técnico y tecnológico }\end{array}$ & $\begin{array}{l}\text { Insertar e incorporar el } \\
\text { tecnológico en en las } \\
\text { productivas }\end{array}$ \\
\hline & 9.- Bolsa de empleo & $\begin{array}{l}\text { Generar nuevas formas y modos de } \\
\text { empleo sustentables en el tiempo } \\
\text { como na herramienta que permita } \\
\text { visualizar las necesidades de capital } \\
\text { humano para las diferentes } \\
\text { actividades mercantiles - económicas. }\end{array}$ \\
\hline & 10.- Observatorio económico & $\begin{array}{l}\text { Determinar un centro de investigación } \\
\text { que permita obtener insumos de datos } \\
\text { estadísticos del sector local, regional y } \\
\text { nacional. }\end{array}$ \\
\hline & $\begin{array}{l}\text { 11.- Banco de desarrollo y } \\
\text { promotor de emprendimiento }\end{array}$ & $\begin{array}{l}\text { Desarrollar las ideas y } \\
\text { emprendimiento existentes para que } \\
\text { los actores económicos disposición } \\
\text { una gama proyectos de inversión y } \\
\text { desarrollo. }\end{array}$ \\
\hline & $\begin{array}{l}\text { 12.- Promoción y comercialización } \\
\text { de productos a través de ferias, } \\
\text { catálogo electrónico. }\end{array}$ & $\begin{array}{l}\text { Conocer la gama de productos sus } \\
\text { beneficios y potencialidades a través } \\
\text { de nuevos sistemas } \\
\text { comercialización }\end{array}$ \\
\hline $\begin{array}{l}\text { 4.- Políticas públicas/ } \\
\text { Sostenibilidad } \\
\text { económica ambiental }\end{array}$ & 13.- Turismo & $\begin{array}{l}\text { Integrar a todos los actores para el } \\
\text { desarrollo del turismo fomentando } \\
\text { facilidades turísticas, equipamientos y } \\
\text { políticas públicas de sostenibilidad. }\end{array}$ \\
\hline
\end{tabular}


ISSN: 2602-8506

Vol. 3, N², p. 47-63, abril - junio, 2019

\begin{tabular}{|l|l|l|}
\hline & $\begin{array}{l}\text { 14.- Políticas de incentivos } \\
\text { tributarios y no tributarios para el } \\
\text { sector productivo }\end{array}$ & $\begin{array}{l}\text { Incentivar el desarrollo económico de } \\
\text { emprendimientos y negocios }\end{array}$ \\
\hline \multirow{2}{*}{$\begin{array}{l}\text { 5.- Alianzas públicas- } \\
\text { privadas }\end{array}$} & $\begin{array}{l}\text { 15.- Proyecto de inversión para la } \\
\text { innovación tecnológica en las } \\
\text { cadenas productivas. }\end{array}$ & $\begin{array}{l}\text { Promover la inversión en la } \\
\text { innovación tecnológica propiciando la } \\
\text { sistematización y automatización de } \\
\text { procesos de producción para } \\
\text { optimizar rendimientos. }\end{array}$ \\
\cline { 2 - 4 } & 17.- Fortalecimiento a los espacios \\
de exposiciones & $\begin{array}{l}\text { Fortalecer los centros de exposiciones } \\
\text { para la promoción continua de nuevos } \\
\text { productos poniendo en la vitrina de la } \\
\text { colectividad y convirtiéndoles en } \\
\text { centro de convenciones. }\end{array}$ \\
\cline { 2 - 4 } & 18.- Centro de Negocios & $\begin{array}{l}\text { Concentrar en una zona industrial los } \\
\text { servicios financieros y públicos para } \\
\text { interrelacionar el desarrollo del sector } \\
\text { productivo }\end{array}$ \\
\hline
\end{tabular}

Fuente: Investigación de campo

Elaborado por: Los Autores

\section{Conclusiones}

- El Desarrollo Económico es uno de los temas que requiere un cambio total en el enfoque y estrategias propuestas, ya que a pesar de la intervención del gobierno local y varias ONGs presentes en el territorio por varios años, aún no se logra consolidar una cultura del emprendimiento o de desarrollo empresarial e industrial. Si bien existen serias limitaciones principalmente en relación al capital necesario para impulsar ideas de empresas, también se evidencia la ausencia de una estrategia permanente que permita resultados a mediano y largo plazo.

- Actualmente existen iniciativas de los sectores productivos basadas en la asociatividad y acuerdos entre miembros de organizaciones económicas, sin embargo, es preciso impulsar la formación de emprendedores, la generación de condiciones de seguridad legal y fomento a las nuevas inversiones, principalmente a través de políticas que atraigan a las empresas, sin recargas impositivas y con facilidades en la dotación de servicios para propiciar un ambiente adecuado para el desarrollo económico productivo.

- Es vital la coordinación y articulación con los otros niveles de gobierno, además de actores privados y Gobiernos de Municipios y provincias con quienes se deben 
establecer pactos para favorecer un crecimiento regional, en base a la complementariedad y no a la competencia.

- Las estrategias de desarrollo económico van articuladas principalmente a las estrategias para el cambio de la matriz productiva. Lamentablemente en el cantón, no se identifican zonas potenciales para las cadenas y productos priorizados como la metalurgia, la minería, hidrocarburos, sin embargo, existen otros sectores que pueden ser potencializados, especialmente la producción primaria desarrollada por los actores de la economía popular y solidaria y el turismo.

\section{Referencias bibliográficas.}

Baca, G. (2010). Evaluaciòn de Proyectos. México: McGraw-Will.

Blanco, C. (2008). Epistemología del Proyecto Factible. Recuperado de: https://entornoempresarial.com/epistemologia-del-proyecto-factible/

Cadena, A. (2016). Estudio de factibilidad para la creación de un centro de acopio de productos órganicos en el centro agricola Cantonal de Riobamba (Tesis de pregrado). Escuela Superior Politécnica de Chimborazo. Riobamba.

Ceballos, V. (2013). Fomentar valores corporativos es esencial para la empresa. Recuperado de http://www.elempleo.com/co/noticias/mundo-empresarial/fomentarvalores-corporativos-es-esencial-para-la-empresa-4384

Cordova, M. (2011). Formulación y Evaluación de Proyectos. Bogotá: Ecoe Ediciones.

Cotán, S., \& Arroyo, P. (2007). Valoración de Impactos Ambientales. Recuperado de http://api.eoi.es/api_v1_dev.php/fedora/asset/eoi:48150/componente48148.pdf

Fajardo, B. (29 de septiembre de 2015). Organigrama Funcional: Definición, $\begin{array}{llll}\text { características } & y & \text { ejemplo. } & \text { Recuperado, }\end{array}$ http://dorganizacionaluni.blogspot.com/2015/09/organigrama-funcionaldefinicion.html

Lara, B. (2011). Como elaborar Proyectos de Inversión paso a paso. Quito: Oseas Espin.

López, F.(2011). Políticas y reglas. Recuperado: de https://soyroiver.wordpress.com/2011/09/17/politicas-y-reglas/

Morales, A., \& Morales, J. (2009). Proyectos de Inversión Evalución y Formulación. México: McGraw-Hill.

Morales, C. (2007). Conceptos de logotipo isotipo e imagotipo. Recuperado, de http://propuestagrafika.blogspot.com/2007/05/conceptos-de-logotipo-isotipo-e.html

Gestión en Recursos Naturales. (2010). Estudios Ambientales. Recuperado, de https://www.grn.cl/estudios-ambientales.html

Padilla, M. (2011). Formulación Evaluación de Proyectos. Bogotá: Ecoe Ediciones.

Pedrosa, S. (2017). Coste de oportunidad. Recuperado de: http://economipedia.com/author/s-jorge

Reyes, A. (2007). Administración Moderna. México: Limusa S.A. 
Samaniego, P. (2015). Plan de desarrollo y ordenamiento territorial del Gobierno Autónomo Descentralizado de la Parroquia San Antonio de Bayushig. Recuperado de: http://app.sni.gob.ec/snilink/sni/PORTAL_SNI/data_sigad_plus/sigadplusdiagnostico/0660820750001_DIA GNOSTICO\%20GAD\%20BAYUSHIG\%202015_14-05-2015_21-16-19.pdf.

Sapag, N. (2011). Proyectos de inversión Formulación y Evaluación. Chile: Pearson. Urueña , O. (2008). Contabilidad Básica. Bogotá: FUS.

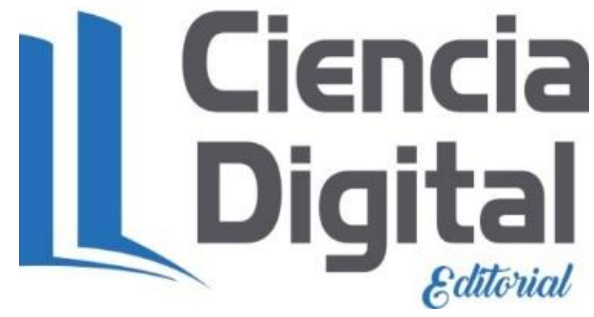


Para citar el artículo indexado.

Pilaguano J., Suárez H., Sánchez M. \& Cevallos W. (2019). Factores que determinan la viabilidad de los emprendimientos., Revista electrónica Ciencia Digital 3(2), 47-63.

Recuperado desde:

http://www.cienciadigital.org/revistascienciadigital/index.php/VisionarioDigital/article/view/393/87 $\underline{7}$

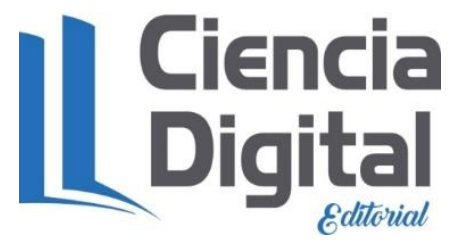

El artículo que se publica es de exclusiva responsabilidad de los autores y no necesariamente reflejan el pensamiento de la Revista Ciencia Digital.

El artículo queda en propiedad de la revista y, por tanto, su publicación parcial y/o total en otro medio tiene que ser autorizado por el director de la Revista Ciencia Digital.
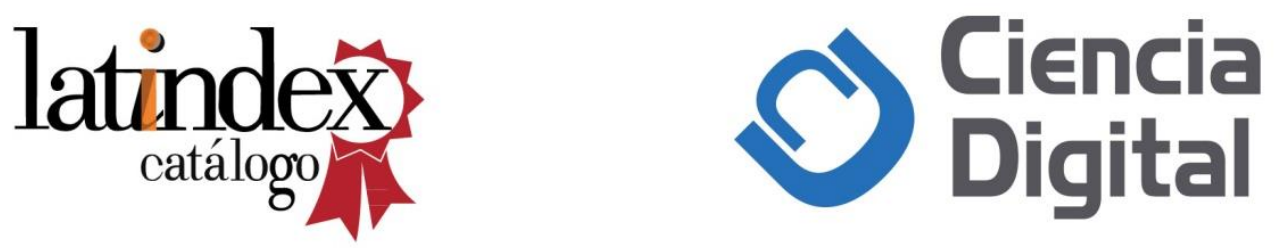